\title{
Consumer ratings and the pricing of experience goods: hedonic regression analysis of beer prices
}

\author{
Rachel A. Smith ${ }^{1,2}$, C. Nicholas McKinney ${ }^{3}$, Steven B. Caudill ${ }^{4,5}$ and Franklin G. Mixon Jr. . $^{*}$
}

\author{
* Correspondence: \\ mixon_franklin@columbusstate.edu \\ ${ }^{6}$ Center for Economic Education, \\ Columbus State University, 4225 \\ University Avenue, Columbus, GA \\ 31907, USA \\ Full list of author information is \\ available at the end of the article
}

\begin{abstract}
This study fills a void in the literature by providing the first evaluation of the impact of consumer ratings on beer prices using hedonic methods. Our work is based on a dataset consisting of over 400 beers and includes information on calorie content, alcohol content, user rating, and style for each beer. Our results indicate that a 10-point increase in consumer rating is associated with about a $\$ 0.50$ increase in the price of beer per unit.
\end{abstract}

Keywords: Experience goods, Hedonic analysis, Beer prices, Consumer ratings, Asymmetric information

\section{Background}

According to a 2014 report by U.S. News \& World Report, worldwide beer consumption tops that of wine by a wide margin, with the former amounting to 187 billion liters per year while the latter totals only 24 billion liters annually (Soergel 2014). ${ }^{1}$ China tops the world's annual beer consumption ranking at 44.2 million kiloliters consumed, followed by the USA ( 24.2 million kiloliters), Brazil (12.8 million kiloliters), Russia (10.6 million kiloliters), and Germany (8.6 million kiloliters). In terms of per capita consumption, nine of the top 10 beerconsuming countries reside in Europe, led by the Czech Republic, whose typical citizen consumes 418 bottles $(12 \mathrm{oz})$ per year. ${ }^{2}$ Despite the worldwide popularity of beer, scholarly study of beer lags far behind that of wine, as represented by the lengthy list of hedonic pricing studies of various aspects of wine that have appeared in the economics literature over the past two decades (e.g., Nerlove 1995, Combris et al. 1997, Landon and Smith 1997, 1998, Anderson and Schamel 2003, Fogarty 2006, Lima 2006, Costanigro et al. 2007, and Costanigro et al. 2009). ${ }^{3}$

Given the importance of beer style variety to consumers of beer, an understanding of the impact on demand of the various characteristics of beer is essential to breweries and retailers. To date, however, the economics literature includes relatively little research using hedonic methods to evaluate beer pricing. ${ }^{4}$ For example, in an unpublished study, Schamel (2009) uses a hedonic model to explain variations in beer prices (per pint) across major cities around the world using attributes and demographics of the city. ${ }^{5}$ More recently, Empen and Hamilton (2015) estimate the effect of games played during the German Bundesliga (soccer) season on the price of beer. Neither of

(c) The Author(s). 2016 Open Access This article is distributed under the terms of the Creative Commons Attribution 4.0 International License (http://creativecommons.org/licenses/by/4.0/), which permits unrestricted use, distribution, and reproduction in any medium, provided you give appropriate credit to the original author(s) and the source, provide a link to the Creative Commons license, and indicate if changes were made. 
these studies, however, shines any substantial light on the importance of various beer characteristics on the prices of domestic and foreign beers.

Going beyond the basic relationship between beer characteristics and beer prices, as firm success in the market for beer relies on repeat purchase behavior, consumer ratings of beer can, given the sequential nature of its consumption, play a useful role in combating the issue of asymmetric information, thus substantially increasing the economic welfare of beer consumers. We are not aware of a study that examines the impact of consumer ratings on beer prices. This study addresses the aforementioned void in the economics literature by employing beer-level data in order to estimate a hedonic price regression model for beer. We investigate the impact of both beer characteristics and consumer ratings on beer prices. Using information from over 400 different beers, we find that, ceteris paribus, higher consumer ratings are associated with higher prices, such that a 10-point increase in an average consumer rating is associated with about a 50-cents increase in the price of a unit (i.e., a six-pack) of beer.

The consumption of beer, much like that of diamonds (see Lee et al. 2014), involves sensory characteristics, such as taste (flavor), weight, and aroma. As such, consumer evaluation of a good such as beer is tied to the economics of information, which has, beginning with the pioneering work of Stigler (1961), Nelson (1970), and Spence (1973), become an important facet of modern microeconomic theory over the past half century. Since these seminal studies, research has shown that, in addition to determining the number and type of informational cues appearing in seller-provided advertisements, the types and characteristics of goods play an important role in pricing. Following Nelson (1970, 1974), search goods are those for which consumers are able to make pre-purchase judgments regarding product attributes/quality at relatively low cost, while experience goods are those for which such judgments can be made by consumers only postpurchase. $^{6}$

The seminal studies comprising the economics of information connect to a more recent study by Che (1996), including an extension by Mixon (1999), that explores consumer learning implications through a mathematical model wherein consumers realize idiosyncratic valuations of the good, such as "buyer's remorse," only after purchase. Following Che (1996), we assume a risk-neutral, profit-maximizing monopoly seller facing a unit mass of customers (consumers) that incurs retail costs of $c \in\left[0, v^{*}\right]$ for each unit of the good (beer), including payments to a distributor. The consumers' preferences for the good (beer) are unknown pre-purchase but are learned post-purchase. A consumer's preference is parameterized by a "valuation," $v$, that is drawn randomly from $[\underline{v}, v *], 0 \leq \underline{v}<v *$, by a distribution function, $F(\cdot)$, which has a well-defined positive density function, $f(\cdot)$ (Che 1996, p. 18). Che (1996, p. 18) notes also that consumers are ex ante identical and that their ex post realized valuations are purely idiosyncratic. Che (1996, pp. 18-19) also considers a simple return policy with a cash refund for any return, which consumers can implement at zero cost.

The von Neumann utility function described in Che (1996, p. 19), which represents a consumer purchasing a good at price $p$ and realizing $v$, is $U(v-p)$, where $U(\cdot)$ is strictly increasing, is (weakly) concave, and exhibits constant absolute risk aversion. The utility from "no purchase" is normalized to be 0 , such that $U(0)=0$ 
(Che 1996, p. 19). Employing a von Neumann utility function and a "no return" policy, the seller's profit is inversely related to the degree of consumer aversion. The consumer will purchase the good (beer) if (and only if) $E[U(v-p)] \geq 0$, where $U$ and $p$ represent utility and price, respectively. Given this, the seller sets a price that covers costs or else chooses not to sell the good (Che 1996, pp. 18-19). Therefore, the optimal price, $p_{\mathrm{n}}$, satisfies $E\left[U\left(v-p_{\mathrm{n}}\right)\right]=0$. Here, (beer) consumers bear the entire risk associated with their ex post valuation, and as risk aversion increases, the seller must lower the price to compensate (beer) consumers for the risk (Che 1996, p. 19).

Given the descriptions accompanying the goods/services included within the searchexperience goods typology, sellers and buyers have, respectively, devised profitmaximizing and acquisition cost-minimizing strategies for overcoming the relatively high pre-purchase costs associated with the evaluation of experience goods such as those described in Che (1996), Mixon (1999), and the current study. Regarding the set of strategies implemented in the experience goods case, studies have shown that sellerprovided informational cues in print advertisements relate indirectly to the attributes of the good by conveying information on various quality-related characteristics of the seller, such as years of service (experience) and licensures/certifications (Mixon 1995).

Additionally, consumer ratings can play a useful role in combating the issue of asymmetric information discussed in the seminal work of Akerlof (1970) by alerting potential consumers of an experience good to its high-quality (low-quality) attributes. ${ }^{7}$ In this regard, the sequential consumption facilitated by the use of consumer reviews has proven to be helpful in lowering the relatively high pre-purchase evaluation costs typically associated with experience goods. In the following section of this study, the impact of consumer reviews on the pricing of beer is examined by testing a hedonic pricing model using a large set of beer-level data.

\section{Methods}

The recent uptick of interest in beer has resulted in the emergence of beer community websites such as beeradvocate.com, ratebeer.com, and The Opinionated Beer Page. These websites offer information about beers and allow consumers to generate feedback on their favorites. The dataset for this study is drawn from the website www.beer.findthebest.com (referred to hereafter as Find the Best), which aggregates data from beeradvocate.com, ratebeer.com, and The Opinionated Beer Page. Find the Best provides characteristics of beers including country of origin, style, average prices, calories, and alcohol content. In addition to these characteristics, which form the foundation of our hedonic pricing model detailed below, Find the Best also provides a "Smart Rating" for most beers. The "Smart Rating" is a weighted average score-between 0 and 100, with higher scores indicating more preferred beers-based on user reviews from the three websites listed above.

After acquiring data from Find the Best and deleting observations with missing variables, our final dataset includes information on 413 different beers. Summary statistics for our dataset are provided in Table 1. Our specification is

$$
\text { AvgPrice }_{i}=\alpha+\beta \text { AvgRating }_{i}+\sum_{j=1}^{k} \gamma_{j} \text { BeerCharact }_{j i}+\sum_{l=1}^{m} \delta_{l} \text { BeerStyle }_{l i}+\varepsilon_{i}
$$

where the dependent variable, Avgrice $_{i}$, is the average price of a unit (i.e., a six-pack) of each beer, $i$, as reported by vendors. The range for AvgPrice $i_{i}$ in our dataset is $\$ 4$ to 
Table 1 Sample statistics

\begin{tabular}{llll}
\hline Variable & American & Foreign & All \\
\hline AvgPrice & $9.589(3.34)$ & $9.140(2.02)$ & $9.542(3.23)$ \\
AvgRating & $78.49(7.33)$ & $69.74(8.85)$ & $77.58(7.95)$ \\
AlchoholVol & $6.228(1.59)$ & $5.079(0.95)$ & $6.109(1.58)$ \\
Calories & $188.6(45.99)$ & $145.2(22.79)$ & $184.1(49.67)$ \\
American & - & - & $0.896(0.31)$ \\
AmericanAle & $0.497(0.50)$ & $0.000(0.00)$ & $0.446(0.50)$ \\
AmericanLager & $0.084(0.28)$ & $0.302(0.46)$ & $0.107(0.31)$ \\
BelgianAle & $0.114(0.32)$ & $0.140(0.35)$ & $0.116(0.32)$ \\
CzechLager & $0.019(0.14)$ & $0.023(0.15)$ & $0.019(0.14)$ \\
EnglishAle & $0.116(0.32)$ & $0.023(0.15)$ & $0.107(0.31)$ \\
EuropeanLager & $0.008(0.09)$ & $0.256(0.44)$ & $0.034(0.18)$ \\
GermanAle & $0.046(0.21)$ & $0.023(0.15)$ & $0.044(0.20)$ \\
GermanLager & $0.073(0.26)$ & $0.093(0.29)$ & $0.075(0.26)$ \\
IrishAle & $0.014(0.12)$ & $0.093(0.29)$ & $0.075(0.15)$ \\
ScottishAle & $0.014(0.12)$ & $0.023(0.15)$ & $0.015(0.12)$ \\
Specialty & $0.014(0.12)$ & $0.023(0.15)$ & $0.017(0.13)$ \\
Nobs & 370 & 43 & 413
\end{tabular}

Figures above are means (standard deviations)

$\$ 42$, with a mean value of $\$ 9.54$. Next, AvgRating $i$ is a weighted average of aggregate ratings for each beer, $i$, that ranges from 50 to 91 in our dataset. The mean rating for the beers in the dataset is 77.58 .

Two separate vectors of beer characteristics variables are included on the right-hand side of (1). The first of these, BeerCharact $t_{j i}$, is a vector of $k$ hedonic pricing characteristics variables, $j$, for each beer, $i$, in our study. Included in this vector are the variables AlcoholVol $_{i}$ Calories $_{i}$, and Country. The first of these, AlcoholVol , is a measure of the alcohol content by volume for each beer. In our dataset, AlcoholVol ${ }_{i}$ has a minimum value of $2.7 \%$, a maximum value of $15 \%$, and an average value of $6.1 \%$, as indicated in Table 1. Next, Calories $_{i}$ is the number of calories in a bottle of each beer, $i$, in our sample. This variable ranges from 55 to 450 , with a mean of about 184.1 (see Table 1). Using the information provided on the country of origin, we created the dummy vari-


and 0 otherwise. Our sample contains 370 beers produced in the USA and 43 foreign beers representing 20 countries. This domestic-to-foreign ratio is the same ratio for all beers represented on Find the Best.

A beer style is "a label given to a beer that describes its overall character and often times its origin (beeradvocate.com)." An ale is a category of beer style that uses yeast that ferments at the "top" of the fermentation vessel at temperatures between 60 and $75{ }^{\circ} \mathrm{F}$, which are temperatures high enough to promote fermentation in 7 days. Ale yeast is recognized for producing distinctive aromas, such as apple, pear, pineapple, grass, hay, plum, and prune (beeradvocate.com). A lager is a category of beer style that uses yeast that ferments at the "bottom" of the fermentation vessel at a temperature of $34{ }^{\circ} \mathrm{F}$. Given that lager produces fewer aroma by-products than ales, other flavors, such as hops, are dominant (beeradvocate.com). Beer styles are well represented in the data, 
with 11 different beer styles including American Ale, American Lager, Belgian Ale, Czech Lager, English Ale, European Lager, German Ale, German Lager, Irish Ale, Scottish Ale, and Specialty. To capture these, BeerStyle $l_{l i}$ is a vector of $m$ beer style dummy variables, $l$, for each beer, $i$, in our study. The dummy variables included in this vector are AmericanAle $_{i}$ (0.445), AmericanLager ${ }_{i}$ (0.107), BelgianAle ${ }_{i}$ (0.116), CzechLager ${ }_{i}$ (0.019), EnglishAle $_{i}$ (0.106), EuropeanLager ${ }_{i}$ (0.034), GermanAle G $_{i}$ (0.044), GermanLager ${ }_{i}(0.075)$, IrishAle $_{i}$ (0.022), ScottishAle $i_{i}$ (0.015), and Specialty ${ }_{i}$ (0.017), with the ratios in parentheses indicating the portion of our dataset accounted for by each beer style, as also indicated in Table 1. In

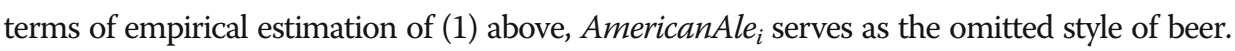

Based on previous research on wine prices, as well as the arguments like those in Tabarrok and Cowen (2015a, 2015b) concerning the usefulness of consumer ratings in mitigating asymmetric information problems, we expect the coefficient for AvgRating ${ }_{i}$ to be greater than 0 . We expect the coefficient of $\mathrm{AlcoholVol}_{i}$ to be greater than 0 , indicating that an increase in alcohol content leads to an increase in price. Due to the presence of beers from very large domestic breweries in our sample, we expect American beers to be cheaper than foreign beers, holding other attributes constant. As such, the coefficient estimate attached to the variable American $_{i}$ is expected to be less than 0 . Similarly, beers that are more expensive to produce, such as specialty beers, should exhibit higher than average prices, meaning that coefficient estimate attached to the variable Specialty $y_{i}$ is expected to be greater than 0 . Lastly, statistically significant beer style coefficients, as captured by the variables in the second vector of (1), will simply reflect differences in consumer preferences. Each of the aforementioned hypotheses is tested in the next section of the study.

\section{Results and discussion}

The results from econometric estimation of (1) are presented in Table 2, beginning with the results from an unrestricted version of the model in column 2 of the table. The $F$-statistic for this model is 3.78 , indicating that the regressors are jointly significant in explaining variations in beer prices. The regressors also work to account for about $12 \%$ of the variation in AvgPrice, as indicated by the $R^{2}$ of $0.117 .{ }^{8}$ In terms of the individual determinants, however, only two variables-AvgRating and AmericanLager-retain their expected signs and are statistically significant, even if only marginally so. While the coefficient of AvgRating, which is the main focus of this study, indicates that a 10-point increase in the average consumer rating for a beer results in an increase in price of about $\$ 0.50$ per unit (i.e., a six-pack), the relatively poor performance of the regression model indicates the possibility that influential observations are present. A cursory exploration of this possibility revealed that the average price of six beers in our sample is $\$ 9.54$, with a standard deviation of $\$ 3.23$. Additionally, our exploration also revealed that the highest price for six beers in our sample is $\$ 42$, which is about 10 standard deviations above the mean.

To more formally investigate the concern that our findings are being influenced by a few observations, we used the DFFITS criterion to search for the presence of influential observations (Belsley et al. 2013). The DFFITS criterion is given by

$$
\text { DFFITS }=\frac{\hat{y}_{i}-\hat{y}_{i(i)}}{s_{(i)} \sqrt{h_{i i}}}
$$

where the $\hat{y}_{i}$ are the prediction points with and without each observation included in the regression, $s_{(i)}$ is the standard error estimated without the observation included, 
Table 2 Hedonic pricing regression results

\begin{tabular}{|c|c|c|c|}
\hline \multirow[b]{3}{*}{ Regressor } & \multicolumn{3}{|c|}{ Dependent variable } \\
\hline & AvgPrice & AvgPrice & AvgPrice \\
\hline & (1) & (2) & (3) \\
\hline Constant & $9.944^{\ddagger}(1.68)$ & $4.290 *(3.31)$ & $3.866 *(3.31)$ \\
\hline AvgRating & $0.054^{\ddagger}(1.74)$ & $0.047^{*}(2.73)$ & $0.050 *(3.21)$ \\
\hline Alcoholvol & $0.444(1.60)$ & $0.341^{\dagger}(2.04)$ & $0.349^{*}(4.07)$ \\
\hline Calories & $-0.002(-0.18)$ & $0.000(0.08)$ & \\
\hline American & $-0.736(-1.22)$ & $-0.696^{\dagger}(-2.54)$ & $-0.566^{\dagger}(-2.29)$ \\
\hline AmericanLager & $-1.197^{\ddagger}(-1.65)$ & $-1.081^{*}(-2.93)$ & $-0.949 *(-2.85)$ \\
\hline BelgianAle & $-0.754(-1.48)$ & $-0.262(-0.73)$ & \\
\hline Czechlager & $-1.501(-1.32)$ & $-1.137^{*}(-3.27)$ & $-1.067^{*}(-3.39)$ \\
\hline EnglishAle & $-0.465(-0.90)$ & $-0.008(-0.03)$ & \\
\hline EuropeanLager & $-0.321(-0.31)$ & $-0.333(-0.82)$ & \\
\hline GermanAle & $-0.161(-0.21)$ & $0.256(0.60)$ & \\
\hline GermanLager & $-0.688(-1.13)$ & $0.269(0.78)$ & \\
\hline IrishAle & $0.679(0.62)$ & $-0.586^{\dagger}(-2.03)$ & $-0.456^{\ddagger}(-1.85)$ \\
\hline ScottishAle & $-0.139(-0.11)$ & $0.542(1.37)$ & \\
\hline Specialty & $1.007(0.78)$ & $0.879^{\ddagger}(1.74)$ & $0.975^{\dagger}(1.99)$ \\
\hline F-statistic & $3.78^{*}$ & $9.56^{*}$ & $14.71^{*}$ \\
\hline$R^{2}$ & 0.117 & 0.223 & 0.218 \\
\hline Nobs & 413 & 400 & 400 \\
\hline
\end{tabular}

Figures in parentheses are $t$-ratios based on robust standard errors (White 1980)

Level of significance: ${ }^{*} 0.01 ;{ }^{\dagger} 0.05 ;{ }^{\ddagger} 0.10$

and $h_{i i}$ is the leverage for the observation, which is a measure of the distance from the other independent variables in the sample. We excluded each observation with an absolute DFFITS value greater than $2 \sqrt{\frac{P}{n}}$, where $P$ is the number of parameters and $n$ is the number of observations (Belsley et al. 2013). Application of this criterion led to the omission of 13 influential observations, reducing our sample to 400 observations.

The econometric results for the re-estimated full model are given in column 3 of Table 2. The F-statistic for this model is 9.56, again indicating that the regressors are jointly significant in explaining variations in beer prices. In this case, the regressors work to account for about $22 \%$ of the variation in AvgPrice, as indicated by the $R^{2}$ of 0.223 . The coefficient estimates of AvgRating, AlcoholVol, American, AmericanLager, CzechLager, and IrishAle are now each statistically significant at the 0.05 level or better. The negative coefficient estimate for CzechLager is not surprising given the concentration of beer production in that country, with the concomitant economies of scale that lead to lower average production costs (Ruddick 2015). The insignificance of EnglishAle and ScottishAle, which are in some cases positively signed (see Table 2), reflect the growth in craft brewing in the UK, where the number of breweries has grown by $50 \%$ in the last 5 years and where $90 \%$ of breweries produce fewer than $5000 \mathrm{hl}$ per year (Ruddick 2015).

The coefficient of our main variable, AvgRating, remains statistically significant and changes little from the estimate obtained using the full sample. The estimate of 0.047 indicates that a 10-point increase in consumer ratings results in an increase in the price of beer per unit of $\$ 0.47$. The coefficient estimate for AlcoholVol is statistically 
significant in this specification as well, indicating that higher alcohol content is associated with higher beer prices. As a form of sensitivity analysis, this version of the model was re-run replacing AvgPrice and AvgRating with logAvgPrice and logAvgRating, respectively. ${ }^{9}$ In this case, the regressors remain jointly significant in explaining variations in beer prices, based on an F-statistic of 8.93. Moreover, the coefficient estimate for $\log$ AvgRating is also positive and statistically significant (at the 0.01 level), thus confirming the prior result in model (2) of Table 2. In terms of the other results, coefficients for American, AmericanLager, and CzechLager are each negative and significant at the 0.01 level, representing a slight improvement over the model (2) results in Table 2. The estimate for IrishAle remains negative but is significant at only the 0.10 level in this case, while AlcoholVol is no longer significant in the log specification. However, the positive coefficient for ScottishAle is significant (at the 0.05 level) when combined with $\log$ AvgPrice and logAvgRating.

Lastly, in order to examine a more parsimonious specification, we re-estimated the previous model without the variables associated with the insignificant coefficients. The results from estimating this model are given in column 4 of Table 2 . The F-statistic increases to 14.71, while the $R^{2}$ falls only marginally, to 0.218 . Again, the coefficient estimate for AvgRating changes only slightly from the prior model. Both models indicate that a 10-point increase in consumer ratings results in an increase in the price of beer per unit of about $\$ 0.50$.

Although the results in the last two columns of Table 2 provide some indication as to the significance of various beer styles in explaining beer prices-with American lager, Czech lager, and Irish ale each priced significantly below American ale-we investigate the importance of beer styles more finely by testing the differences in the parameter estimates in model 2 of Table 2. The results of these tests for various styles of ale are presented in Table 3. As indicated there, Scottish ale is significantly more expensive than either American Ale or Belgian ale, while Irish ale is priced significantly below each other styles of ale with the lone exception of Belgian ale. Similar comparisons are made for lager, with the results shown in Table 4. As indicated there, both European lager and German lager are significantly more expensive than either American lager or Czech lager, while the estimated price difference of $\$ 0.602$ between the former two lagers (i.e., European and German) is marginally insignificant.

\section{Conclusions}

This study is the first to investigate the impact of user ratings on the pricing of beer using a hedonic regression model and a large dataset consisting of beer-level data.

Table 3 Ale price difference estimates

\begin{tabular}{llllll}
\hline & ScottishAle & GermanAle & AmericanAle & EnglishAle & BelgianAle \\
\hline GermanAle & $0.286(0.49)$ & & & & \\
AmericanAle & $0.542(1.37)$ & $0.256(0.60)$ & & & \\
EnglishAle & $0.550(1.15)$ & $0.264(0.52)$ & $0.008(0.03)$ & & \\
BelgianAle & $0.804(1.51)$ & $0.518(0.93)$ & $0.262(0.73)$ & $0.254(0.57)$ & \\
IrishAle & $1.128(2.30)$ & $0.842(1.63)$ & $0.586(2.03)$ & $0.578(1.47)$ & $0.324(0.70)$ \\
\hline
\end{tabular}

In each case, the parameter difference is calculated by subtracting the parameter estimate for the variable in a given row from that for the variable at the head of the column. Figures in parentheses are $t$-ratios. Italic font denotes the 0.10 level (or better) of significance (one-tailed test) 
Table 4 Lager price difference estimates

\begin{tabular}{llll}
\hline & GermanLager & EuropeanLager & AmericanLager \\
\hline EuropeanLager & $0.602(1.13)$ & & \\
AmericanLager & $1.350(2.67)$ & $0.748(1.36)$ & \\
CzechLager & $1.406(2.87)$ & $0.804(1.50)$ & $0.056(0.11)$ \\
\hline
\end{tabular}

In each case, the parameter difference is calculated by subtracting the parameter estimate for the variable in a given row from that for the variable at the head of the column. Figures in parentheses are $t$-ratios. Italic font denotes the 0.10 level (or better) of significance (one-tailed test)

Based on the theoretical construct provided by the economics of information, and including in the empirical analysis independent variables such as calorie content, alcohol content, consumer ratings, and dummy variables for beer style, econometric results suggest that consumer ratings are positively and significantly related to beer prices across all specifications. More specifically, our results indicate that a 10-point increase in consumer ratings leads to about a $\$ 0.50$ increase in the price of a beer per unit.

The econometric results presented in this study suggest that manufacturers and retailers of experience goods, such as beer, should encourage the further development of "information markets" where consumers are able to provide information about product attributes to potential future consumers. Additionally, the positive and significant findings for consumer ratings in this study suggest that beer distributors and retailers might benefit from placement of consumer ratings information in advertisements and other product-related media. This type of information cue could exist alongside other, more indirect, cues about the attributes of the product. Future research on the prevalence of this phenomenon would represent a useful extension of the empirical research in this particular genre of the economics literature.

\section{Endnotes}

${ }^{1}$ These totals translate to two bottles of beer consumed for every glass of wine consumed (Soergel 2014).

${ }^{2}$ The exception is Venezuela, which ranks eighth among all countries (Soergel 2014).

${ }^{3}$ Some of the earlier hedonic pricing studies in this genre have examined the impact of user-generated feedback. Nerlove (1995) and Combris et al. (1997), for example, find that taster evaluations of wine are statistically insignificant, while studies by Landon and Smith $(1997,1998)$ and Anderson and Schamel (2003) find that long-term reputation and vintage ratings significantly influence the amount consumers who are willing to pay for wine.

${ }^{4}$ Some studies are on the periphery of hedonic price modeling. For example, Lopez and Matschke (2012) examine 30 brands of beer sold in 12 US cities over the 19881992 period in order to test the impact of certain beer characteristics (e.g., alcohol content, calories), including beer prices, on consumer satisfaction (utility). Other studies fall further from the hedonic pricing genre, such as Tomlinson and Branston (2014), which uses macro-level data to estimate price elasticities in the UK beer market.

${ }^{5}$ Schamel includes Anholt's City Brand Index and relative price levels measured by the Big Mac Index. Employing price data from PintPrice.com, Schamel (2009) finds that a one-point increase in the attractiveness of the city increases the price of beer by about 8 cents and that the relative price level in a city is positively correlated with a beer's price. 
${ }^{6}$ Darby and Karni (1973) consider a third category of goods-credence goods-which comprise those goods and services for which even post-purchase judgments may be difficult, if not impossible, for consumers.

${ }^{7}$ For an insightful discussion on the role played by consumer reviews and other mechanisms in battling asymmetric information, see Tabarrok and Cowen (2015a, 2015b).

${ }^{8}$ As we are interested in explaining variations in beer prices on the basis of their characteristics, not predicting them, the $F$-statistic is much more appropriate than $R^{2}$ as a measure of the quality of our empirical modeling.

${ }^{9}$ For brevity, these results are not reported in Table 2.

\section{Acknowledgements}

The authors thank two anonymous referees of this journal for the helpful comments on a previous version. Any remaining errors are their own. Lastly, the first author's affiliation with Square, Inc., is provided for information purposes only and is not intended to convey or imply Square's concurrence with, or support for, any viewpoints expressed by the authors.

\section{Authors' contributions}

RAS collected the data, participated in the analysis of the data, and participated in the drafting of the manuscript. CNM participated in the analysis of the data. SBC participated in the analysis of the data and in the drafting of the manuscript. FGM participated in the analysis of the data and in the drafting of the manuscript.

\section{Authors' information}

Rachel A. Smith is a product analyst at Square, Inc. She is also affiliated with the University of San Francisco. C. Nicholas McKinney is an associate professor of economics at Rhodes College. His research has appeared in Games and Economic Behavior, Journal of Economic Behavior and Organization and Experimental Economics. Steven B. Caudill is the Barry and Carole Kaye Distinguished Professor of Economics at Florida Atlantic University. His previous work is published in the American Journal of Agricultural Economics, Journal of Econometrics, and Review of Economics and Statistics. Franklin G. Mixon, Jr. is a professor of economics at Columbus State University. His research has appeared in Resource and Energy Economics, Journal of Economic Perspectives, and Journal of Money, Credit, and Banking.

\section{Competing interests}

The authors declare that they have no competing interests.

\section{Author details}

${ }^{1}$ Department of Mathematics and Statistics, University of San Francisco, San Francisco, CA, USA. ${ }^{2}$ Product Analysis Division, Square, Inc., Oakland, CA, USA. ${ }^{3}$ Department of Economics, Rhodes College, Memphis, TN, USA. ${ }^{4}$ Department of Economics, Florida Atlantic University, Boca Raton, FL, USA. ${ }^{5}$ Department of Economics, University of Sassari, Sassari, Sardinia, Italy. ${ }^{6}$ Center for Economic Education, Columbus State University, 4225 University Avenue, Columbus, GA 31907, USA.

Received: 3 December 2015 Accepted: 30 October 2016

Published online: 09 November 2016

\section{References}

Akerlof GA (1970) The market for lemons: quality uncertainty and the market mechanism. Q J Econ 84(3):488-500

Anderson K, Schamel G (2003) Wine quality and varietal, regional and winery reputations: hedonic prices for Australia and New Zealand. Econ Rec 79(246):357-369

Belsley, DA, Kuh, E and Welsch, RE (2013) Regression diagnostics: identifying influential data and sources of multicollinearity. New York, NY: Wiley-Interscience.

Che Y-K (1996) Customer return policies for experience goods. J Ind Econ 44(1):17-24

Combris P, Lecocq S, Visser M (1997) Estimation of a hedonic price equation for Bordeaux wine: does quality matter? Econ J 107(441):390-402

Costanigro M, McCluskey J, Mittelhammer RC (2007) Segmenting the wine market based on price: hedonic regression when different prices mean different products. J Agric Econ 58(3):454-466

Costanigro M, Mittelhammer RC, McCluskey J (2009) Estimating class-specific parametric models under class uncertainty: local polynomial regression clustering in an hedonic analysis of wine markets. J Appl Economet 24(7): $1117-1135$

Darby MR, Karni E (1973) Free competition and the optimal amount of fraud. J Law Econ 16(1):67-88

Empen J, Hamilton SF (2015) How do retailers price beer during periods of peak demand? Evidence from game weeks of the German Bundesliga. South Econ J 81(3):679-696

Fogarty J (2006) The return to Australian fine wine. Eur Rev Agric Econ 33(4):542-561

Landon S, Smith CE (1997) The use of quality and reputation indicators by consumers: the case of Bordeaux wine. J Consum Policy 64(3):628-647

Landon S, Smith CE (1998) Quality expectations, reputation, and price. South Econ J 64(3):289-323

Lee JA, Caudill SB, Mixon FG Jr (2014) Shine bright like a diamond: a hedonic model of grading and pricing an experience good. Appl Econ 46(16):1829-1838

Lima, T (2006) Price and quality in the California wine industry: an empirical investigation. Journal of Wine Economics 1(2):176-90.

Lopez RA, Matschke X (2012) Home bias in US beer consumption. Pac Econ Rev 17(4):525-534 
Mixon FG Jr (1995) Advertising as information: further evidence. South Econ J 61(4):1213-1218

Mixon FG Jr (1999) Customer return policies for experience goods: the impact of product price and consumer search costs on seller-provided informational cues. Appl Econ 31(3):331-336

Nelson P (1970) Information and consumer behavior. J Polit Econ 78(2):311-329

Nelson P (1974) Advertising as information. J Polit Econ 82(4):729-754

Nerlove M (1995) Hedonic price functions and the measurement of preferences: the case of Swedish wine consumers. Eur Econ Rev 39(9):1697-1716

Ruddick, G (2015) Beer titans opt to merge as trend for smaller craft brews comes to a head. The Guardian, October 17, https://www.theguardian.com/business/2015/oct/17/sabmiller-ab-inbev-megabrew-craft-beer-ale-pubs. Accessed 7 Nov 2016.

Schamel, G (2009) A simple hedonic model of beer prices for major cities around the world. Beeronomics Conference, Leuven, Belgium May 27-29, 2009.

Soergel, A (2014) Which country drinks the most booze? U.S. News \& World Report, October 2, http://www.usnews.com/ news/blogs/data-mine/2014/10/02/drinking-data-shows-us-at-the-top-by-volume-but-europe-dominates-per-capita. Accessed 7 Nov 2016.

Spence M (1973) Job market signaling. Q J Econ 87(3):355-379

Stigler GJ (1961) The economics of information. J Polit Econ 69(3):213-225

Tabarrok, A and Cowen, T (2015a) The end of asymmetric information. Cato Unbound: A Journal of Debate, http:// www.cato-unbound.org/2015/04/06/alex-tabarrok-tyler-cowen/end-asymmetric-information. Accessed 7 Nov 2016.

Tabarrok, A and Cowen, T (2015b) Symmetric information won't be perfect. Cato Unbound: A Journal of Debate, http:// www.cato-unbound.org/2015/04/20/alex-tabarrok-tyler-cowen/symmetric-information-wont-be-perfect. Accessed 7 Nov 2016.

Tomlinson PR, Branston BJ (2014) The demand for U.K. beer: estimates of the long-run on- and off-trade beer price elasticities. Appl Econ Lett 21(3):209-214

White $H$ (1980) A heteroskedasticity-consistent covariance matrix estimator and a direct test for heteroskedasticity. Econometrica 48(4):817-838

Submit your manuscript to a SpringerOpen ${ }^{\circ}$ journal and benefit from:

- Convenient online submission

Rigorous peer review

Immediate publication on acceptance

- Open access: articles freely available online

- High visibility within the field

- Retaining the copyright to your article

Submit your next manuscript at $>$ springeropen.com 